\title{
Land Use/Land Cover Analysis Based on Various Comprehensive Geospatial Data Sets: A Case Study from Tirupati Area, South India
}

\author{
Nagaraju Arveti', Balaji Etikala1, Padmanava Dash ${ }^{2}$ \\ ${ }^{1}$ Department of Geology, Sri Venkateswara University, Tirupati, India \\ ${ }^{2}$ Department of Geosciences, Mississippi State University, Mississippi State, MS, USA \\ Email: arveti@yahoo.com
}

Received 26 March 2016; accepted 13 May 2016; published 16 May 2016

Copyright (C) 2016 by authors and Scientific Research Publishing Inc.

This work is licensed under the Creative Commons Attribution International License (CC BY).

http://creativecommons.org/licenses/by/4.0/

c) (i) Open Access

\begin{abstract}
Land use/land cover (LULC) information is essential for the selection, planning and implementation of management strategies to meet the increasing demands for basic human needs and welfare of the ever growing population. This paper illustrates the status of land use/land cover in the Tirupati area of Andhra Pradesh state using an integrated approach of remote sensing and Geographic Information System (GIS). The National Land use/Land cover classification developed by National Remote Sensing Centre (NRSC) and Indian Space Research Organisation (ISRO) divides the land in the study area into five Level I classes, 11 Level II classes, and fifteen Level III classes. From this three-level hierarchic based classification, it was found that the Forest is the major LULC category in the Tirupati area covering $227.46 \mathrm{~km}^{2}(58.55 \%)$, followed by Agricultural land, Wastelands, Built-up land and water bodies contributing to $70.36 \mathrm{~km}^{2}(18.11 \%), 43.92 \mathrm{~km}^{2}$ $(11.31 \%), 32.71 \mathrm{~km}^{2}(8.42 \%)$ and $14.03 \mathrm{~km}^{2}(3.61 \%)$ respectively of the total geographical area. This study also reviewed the characteristics of urban sprawl and their impacts on quality of life, the evident driving forces and its impact on development activities. The study concludes that in Tirupati area forest land contributed the highest land cover $(58.55 \%)$, while the lowest was contributed by water bodies $(3.61 \%)$ and shows a significant impact of urbanization on the ecosystem.
\end{abstract}

\section{Keywords}

Remote Sensing, GIS, Landuse/Land Cover, Tirupati 


\section{Introduction}

Human alterations of the environment over the past few decades have grown exponentially since industrial revolution took place. While earth's landmass has remained factually static over the time, the human demands on it have grown and altered, impacting the earth's ecosystem in numerous ways. Hence, adequate information on land use/land cover and its alterations to the environment has become an important aspect as the Nation plans to overcome the problems of haphazard, uncontrolled development, deteriorating environmental quality, loss of prime agricultural lands, destruction of important wetlands, and loss of fish and wildlife habitat. In the last three decades, the technologies and methods of remote sensing have evolved dramatically to include a suite of sensors operating in a wide range of imaging scales with potential interest and importance to planners and land managers [1].

Current remote sensing technology offers collection and analysis of data from ground-based, atmospheric, and Earth-orbiting platforms, with linkages to GPS data, GIS data layers, and functions, and emerging modelling capabilities [2]. Remote sensing information, in concert with available, enabling technologies such as GPS and GIS, can form the information base upon which sound planning decisions can be made, while remaining costeffective [3]. This has made remote sensing a valuable source of land cover and land use information. Land use/ land cover is two separate terminologies which are often used interchangeably [4]. In general, land cover is defined as the observed (bio)-physical cover on the Earth's surface. It includes vegetation and man-made features as well as bare rock, bare soil, and inland water surfaces [5]. While land use refers to the way in which land has been used by humans and their habitat, usually with the accent on the functional role of land for economic activities. Land use/land cover data sets are primary inputs for environmental modelling and monitoring, natural resources management, policy-making, carbon cycle studies, hydrology and global climate change analysis [6]. Roy Haines-Young [7] wrote these words with great emphasis in one of his earlier works; notions of "land functions" [8], "land use functions" [9], and "landscape function" [10]-[12] have emerged as a way of tracing the connections between land and the ecological systems and their functional response. Historical land use and land cover and its changes that are being altered by human activities have a significant impact on the Earth's landscape, perturbing energy, moisture, and chemical fluxes which impact the Earth's climate. Earlier studies show the spatial land use/land cover changes and their implications on climatic variables [13]-[15].

The urban ecosystem is strongly influenced by the spatial reach of human alterations. Economic opportunities and constraints created by regional and global market policies are one of the determinants in amplifying and attenuation of urban ecosystems. In reality, urbanization affects land change elsewhere through the transformation of urban-rural linkages [16]. Extended peri-urban settlements and a large influx of demographic transformation into urban areas led to the excess urban sprawl. The uncontrolled urban sprawl and transformations of land use in peri-urban areas have strong negative impacts on all the natural, economic and social components [17]. Unprecedented population growth rate exerts pressure on land resulting flimsy cohesion among environmental variables [18]. Land degradation by tourism development and transition of agricultural land into settlements ensuing huge alters to the environment. This change adversely affects local/regional/global environment. The urban lifestyles tend to raise consumption expectations and that $60 \%$ of the world's population will be urban by 2025 [19]. Large-scale urban agglomerations and extended peri-urban settlements fragment the landscapes of such large areas that various ecosystem processes are threatened [16].

The study area is one of the fastest developing cities in Andhra Pradesh and has witnessed a substantial increase in population, economic growth, industrialization, and transportation activities in recent years which show a negative impact on the environment. Urbanization, tourism development activities as it is one of the world famous pilgrim centre, human population growth, and demand for forest products have been important drivers of land use/land cover change in the study area. Several other scenarios like the demand for locally produced food, global issues such as higher energy prices and climate change are influencing the urban ecosystem. In the study area, population projections suggest that the increase in urban sprawl will also increase in rural areas, possibly because of people commuting between work in urban areas and countryside homes. Significant expansion of built-up area, decrease in agricultural area, water spread area and forest areas. It clearly indicates the significant impact of population and its development activities on quality of life [20].

The common understanding of LU/LC, the causes of land use and land-cover change and its interrelated aspects have become increasingly important as which, in turn, underlie many environment-development policies. Remote sensing and GIS are powerful tools to derive accurate and timely information on the spatial distribution 
of land use/land cover. GIS provides a flexible environment for collecting, storing, displaying and analyzing digital data necessary for LU/LC detection [21]. With the invention of remote sensing and GIS techniques, land use/land cover mapping is a useful and detailed method to improve the selection of areas designed for agricultural, urban and industrial areas of a region [22].

Hence, proper information on LU/LC is necessary for implementing various developments, planning, and land use schemes to meet up the increasing demands of basic human needs. Tirupati a holy city of Andhra Pradesh State and its surroundings area was chosen for the study because of its remarkable population growth, expansion of industry, transport, economic, tourism and being an educational hub. Hence, an attempt has been made to analyze the urban sprawl, monitoring the dynamics of LU/LC, its changes and the pathways that impact the urban ecosystems.

\section{Study Area}

Tirupati $\left(13^{\circ} 34^{\prime}-13^{\circ} 45^{\prime} \mathrm{N}, 79^{\circ} 15^{\prime}-79^{\circ} 29^{\prime} \mathrm{E}\right)$ is the world famous pilgrimage centre of Lord Sri Venkateswara Swamy and is one of the fastest developing cities located at the foothills of the Seshachalam hill range in Chittoor district of Andhra Pradesh. The population of the study area grew between 1981, 1991, 2001 and 2011 at a rate of 1.91 percent annually and it has witnessed a substantial increase in urbanisation, industrialization, economic growth and transportation activities which shows a negative impact on the environment [20]. It covers an area of about $388.48 \mathrm{~km}^{2}$ and consists of Tirupati rural and urban areas. This area has a semi-arid climate. The summer temperature ranging from 35 to 40 degrees Celsius and the winter temperature varies from 18 and 20 degrees Celsius. The city experiences extreme rainfall in November during the northeast monsoon season with an average annual rainfall of 979 and $1088 \mathrm{~mm}$ of Tirupati rural and urban areas respectively. Shallow gravelly reddish brown soils are predominant in the study area over the granites and gneisses of peninsular gneissic complex, quartzites, shales/phyllites and limestones of the Cuddapah super group. Figure 1 shows the location map of the study area.

\section{Materials and Methods}

Various comprehensive geospatial data sets were used to produce a thematic LU/LC map of the study area. This includes IRS P6 LISS IV satellite data of 2012 with $5.8 \mathrm{~m}$ spatial resolution and Survey of India SOI topographic maps $57 \mathrm{O} / 5$ and $57 \mathrm{O} / 6$ of 1:50,000 scales. The methodology followed was on-screen digitization using visual image interpretation elements like tone, texture, size, shape, pattern, association etc. (Table 1) and Arc GIS 10 version software. Figure 2 shows the schematic diagram of the methodology followed.

\section{Classification Scheme}

In order to get the comprehensive output, the National LU/LC classification system of NRSC and ISRO has been employed [23]. This classification divided all land types in the study area to be 5 kinds of Level I class land type 11 kinds of Level II class land type and 15 kinds of Level III class land type. Table 2 shows the Land use/Land cover classification levels.

\subsection{Results and Discussion}

For the better comprehensive development and management of the Tirupati and its surrounding areas, it is needed to have proper information on LU/LC and the driving forces that affect the urban ecosystem. IRS P6 LISS IV data of 1:50,000 scale for the year 2012 was visually interpreted for the delineation of LU/LC categories of the study area. The various LU/LC classification levels based on visual interpretation in the study area includes Built-up land, Agricultural land, Forest land, Water bodies, Wastelands. The statistical distribution of LULC categories of Tirupati area is depicted in Table 3 and the land use/land cover map of Tirupati area is shown in Figure 3.

\subsubsection{Built-Up Land}

The built-up land is described as an area of human habitation developed by virtue of non-agricultural use. It consists of buildings, transport, and communication, utilities in association with water, vegetation and vacant 


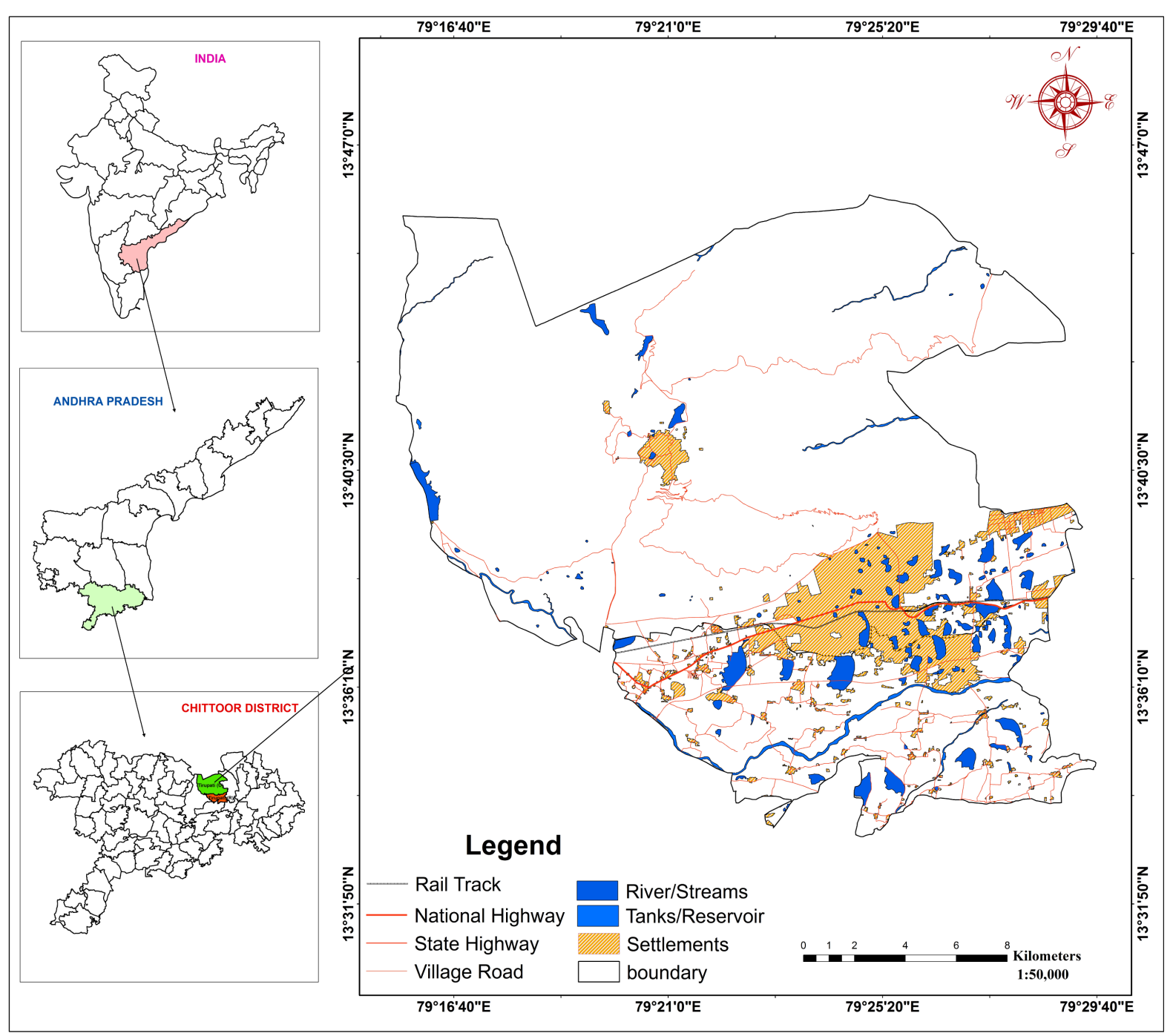

Figure 1. Location map of the study area.

lands [24]. Rural and urban built-up lands are the main sub categories identified under this category. Built-up land is composed of areas of intensive with much of the land covered by structures and it covers an area of 32.71 $\mathrm{km}^{2}$ (8.42\%) (Table 3). Cities, towns, villages, industrial and commercial complexes and institutions are included in this category. Tiruchanur, Mangalam, Cherlopalle, Avilala, Tirupati and Tirumala are the major villages and towns located in the study area and are well connected by road and railways.

\subsubsection{Built-Up Land Urban}

In the study, an urban area is characterized by high human population density and vast human-built features in contrast to the areas surrounding it. Urban areas may be cities, towns or conurbations, but the term is not commonly extended to rural settlements such as villages and hamlets. It covers an area of $12.02 \mathrm{~km}^{2}$ (3.19\%). Core urban and peri-urban are the identified subcategories under this category. Urban cores are defined as areas with high population densities (2900 per square kilometre or more) and high transit, walking and cycling work trip market shares (20 percent or more). The peri-urban areas as those areas adjacent to built-up areas of high population concentrations (that is, urban), they specified that they are the zones where traditional farming activities come into conflict with alternative economic, residential and recreational interests [25]. The geographical extents of core urban and peri-urban sub categories are about $11.94 \mathrm{~km}^{2}$ (3.07\%) and $12.11 \mathrm{~km}^{2}$ (3.12\%) respectively. 
Table 1. On-screen digitization using visual image interpretation elements.

\begin{tabular}{|c|c|c|c|c|c|}
\hline LU/LC category & Tone & Texture & Size & Shape & Pattern \\
\hline Built-up (rural) & Bluish green & Coarse to mottled & Small to big & Irregular & Clustered to scattered \\
\hline Built-up (urban) & $\begin{array}{l}\text { Dark to very dark } \\
\text { bluish green }\end{array}$ & Smooth to fine & Small in width & Regular & Linear \\
\hline $\begin{array}{c}\text { Built-up } \\
\text { mining/industrial }\end{array}$ & Blackish green & Course & Small to big & Irregular & $\begin{array}{l}\text { Contiguous to } \\
\text { non-contiguous }\end{array}$ \\
\hline Cropland & Bright red to red & Medium to Smooth & Small to big & Regular to irregular & $\begin{array}{l}\text { Contiguous to } \\
\text { non-contiguous }\end{array}$ \\
\hline Agricultural plantation & Light red to red & Smooth to medium & Varying in size & Regular, sharp edges & $\begin{array}{l}\text { Contiguous to } \\
\text { non-contiguous }\end{array}$ \\
\hline Forest land & Red to dark red & Coarse & Varying in size & Regular to irregular & $\begin{array}{l}\text { Contiguous to } \\
\text { non-contiguous }\end{array}$ \\
\hline Reservoir/lake/canal & Light blue to dark blue & Smooth to mottled & $\begin{array}{l}\text { Small, medium to } \\
\text { large }\end{array}$ & Regular to irregular & $\begin{array}{c}\text { Dispersed except canals } \\
\text { which show a linear } \\
\text { pattern }\end{array}$ \\
\hline River/stream & Light blue to dark blue & Smooth to medium & $\begin{array}{l}\text { Long and narrow to } \\
\text { wide }\end{array}$ & Irregular to sinuous & $\begin{array}{l}\text { Contiguous, non-linear to } \\
\text { dendritic/sub-dendritic }\end{array}$ \\
\hline Barren rocky & $\begin{array}{l}\text { Greenish blue to yellow } \\
\text { to brownish }\end{array}$ & $\begin{array}{l}\text { Very coarse to coarse } \\
\text { to medium }\end{array}$ & $\begin{array}{l}\text { Varying in } \\
\text { Size }\end{array}$ & Irregular & $\begin{array}{c}\text { Linear to contiguous and } \\
\text { dispersed }\end{array}$ \\
\hline Salt affected & White to light blue & $\begin{array}{l}\text { Smooth, to mottled } \\
\text { texture, }\end{array}$ & Small to medium & $\begin{array}{c}\text { Irregular and } \\
\text { discontinuous shape }\end{array}$ & $\begin{array}{c}\text { Dispersed and } \\
\text { non-contiguous }\end{array}$ \\
\hline Scrubland & $\begin{array}{l}\text { Light yellow to brown } \\
\text { to greenish blue }\end{array}$ & Coarse & $\begin{array}{l}\text { Varying in } \\
\text { Size }\end{array}$ & Regular to irregular & $\begin{array}{l}\text { Contiguous to } \\
\text { non-contiguous }\end{array}$ \\
\hline
\end{tabular}

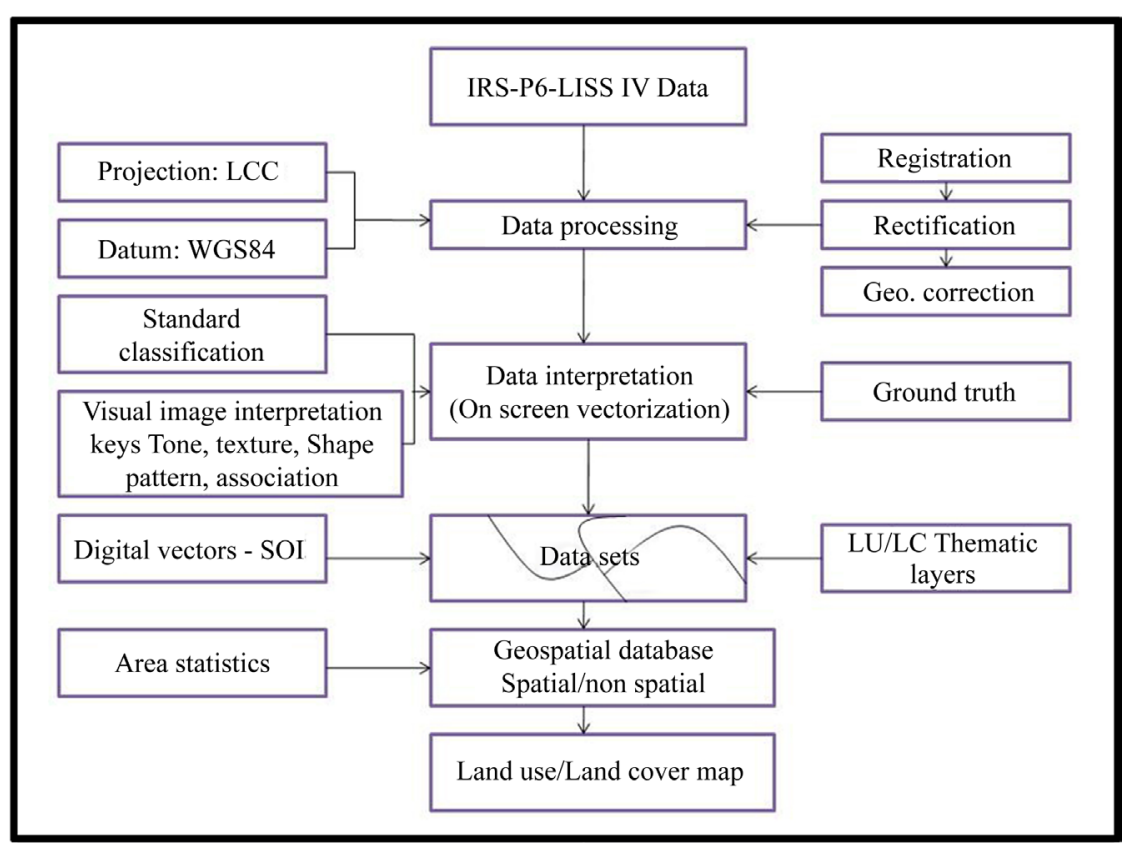

Figure 2. Schematic diagram.

\subsubsection{Built-Up Land Rural}

The rural area is characterized by agricultural and allied sectors and non-commercial activities with population size less than 5000 generally lack supporting facilities. Most of the people are involved in the primary activity of agriculture. Village, hamlets/dispersed households are the identified sub categories. The Village is a small group of households in a rural area usually larger than a hamlet. The areas covered under village/hamlet/dispersed household categories are about $7.38 \mathrm{~km}^{2}(1.90 \%)$. 
Table 2. Land use/land cover classification levels based on NRSC and ISRO (2011).

\begin{tabular}{ccc}
\hline Level - I & Level - II & Level - III \\
\hline Built-up & Built-up (urban) & Built-up/core urban/peri-urban \\
& Built-up (rural) & Village/hamlets/dispersed house hold \\
Mining/industrial area & Industrial mine/quarry \\
Agricultural land & Agriculture plantation & Agriculture plantation \\
Forest land & Cropland & Cropland \\
& Forest & Forest \\
Water bodies & Reservoir/tanks & Reservoir/tanks \\
& River/stream/drain & River/stream/drain \\
Wastelands & Barren rocky & Barren rocky \\
& Salt affected & Salt affected \\
\hline
\end{tabular}

Table 3. Statistical distributions of land use/land cover categories of the study area.

\begin{tabular}{ccc}
\hline LU/LC category & Area in $\left.\mathbf{( k m}^{\mathbf{2}}\right)$ & \% to total geographical area (TGA) \\
\hline Core urban & 11.94 & 3.07 \\
Peri-urban & 12.11 & 3.12 \\
Village/hamlets/dispersed house hold & 7.38 & 0.33 \\
Industrial mine/quarry & 1.28 & 2.44 \\
Agricultural plantation & 9.48 & 15.67 \\
Cropland & 60.88 & 58.55 \\
Forest & 227.46 & 2.86 \\
Reservoir/tanks & 11.12 & 0.75 \\
River/stream/drain & 2.91 & 0.18 \\
Barren rocky & 0.70 & 0.30 \\
Salt affected & 1.18 & 3.08 \\
Open scrub & 11.98 & 7.74 \\
Dense scrub & 30.06 & 100.00 \\
Total & 388.48 & 28 \\
\hline
\end{tabular}

\subsubsection{Mining and Industrial Area}

These are characterized by the removal of surface and sub-surface earth material by manual and mechanized operations. This constitutes a negligible percent of total geographical extent $1.28 \mathrm{~km}^{2}(0.33 \%)$.

\subsection{Agricultural Land}

Agricultural land is described as the land primarily used for farming and for the production of food, fibre, and other commercial and horticultural crops. It includes land under crops (irrigated and unirrigated, fallow, plantations etc). In the study area, agricultural land includes agricultural plantations and croplands. 


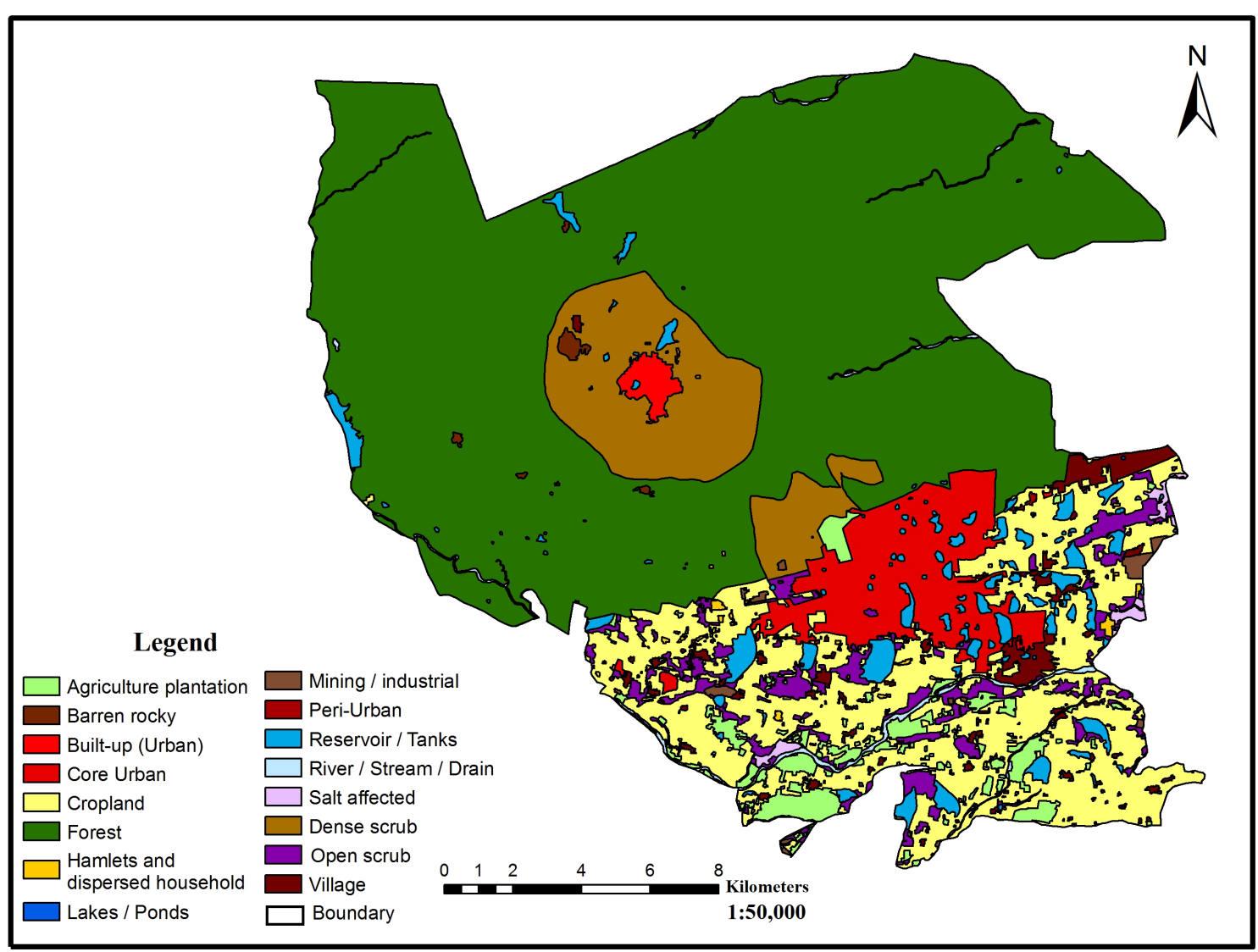

Figure 3. Land use/land cover map of the study area.

\subsubsection{Agricultural Plantation}

Agricultural Plantation is defined as an area under agricultural tree crops planted adopting certain agricultural management techniques. Mango and eucalyptus plantation are the dominant plantation type in the study area. Plantation appears in light-red to red in tone on satellite imagery. These are identified by its tone of different sizes with regular and sharp edges which are an indication of a fence around it. In the present study, the plantation occupies an area of about $9.48 \mathrm{~km}^{2}(2.44 \%)$.

\subsubsection{Cropland}

Cropland includes those lands with standing crop as on the date of the satellite overpass. The crops can be of either Kharif or Rabi or Kharif Rabi seasons. Cropped land appears in bright red to red in colour with varying shape and size in contiguous to non-contiguous in the pattern. In the present study, the cropland occupies an extent of about $60.88 \mathrm{~km}^{2}$ (15.67\%). Wet cultivation is the dominant land use category in the study area.

\subsection{Water Bodies}

The water bodies include both natural and man-made water features such as ponds, lakes, tanks and reservoirs flowing as streams, rivers, and canals etc. This category comprises areas with surface water, either impounded in the form of ponds, lakes and reservoirs or flowing as streams, rivers, and canals etc. Water bodies are represented by light blue to dark blue in tone and smooth to mottled texture on satellite imagery. Water bodies appear dark on satellite imagery due to absorption of incoming IR radiation. Surface water bodies such as tanks/reservoirs and river/stream/drains are identified in the study area and their geographical distributions are $11.12 \mathrm{~km}^{2}$ (2.86\%) hectares and $2.91 \mathrm{~km}^{2}$ (0.75\%) respectively. Papavinasanam, Gogarbham, Akasa Ganga, Kumaradhara, Pasupudhara, Kalyani dam and Sri Sai Ganga canal under the Telugu Ganga project are the prime drinking water resources of Tirumala and Tirupati areas. 


\subsection{Forest}

These are the areas bearing an association predominantly of trees and other vegetation types (within the notified forest boundary). In the satellite image, such forest is identified by red to dark red in tone with a coarse texture. This class is distributed in the northern part of the study area. Forest land contributed the predominant land cover category in the study area and it covers an area of about $227.46 \mathrm{~km}^{2}$ (58.55\%).

\subsection{Wasteland}

Wasteland may be described as degraded land underutilized lands most of which could be brought into productive use with proper soil and water management practices [26] or the land which is deteriorating due to lack of appropriate water and soil management or on account of natural causes [27]. Wastelands can result from inherent/imposed disabilities such as by location, environment, chemical and physical properties of the soil or financial or management constraints. In the study area, three main wasteland categories are predominantly observed. Barren rocky, salt affected, scrubland are listed under this category.

\subsubsection{Barren Rocky}

Barren rocky is described as the rock exposures of varying lithology often barren and devoid of soil cover with limited capacity to support life and having less than 5 percent vegetative cover. They occur amidst hill forests as openings or scattered as isolated exposures or loose fragments of boulders or as sheet rocks on plateau and plains. In the present study barren rocky occupies an area of about $0.70 \mathrm{~km}^{2}(0.18 \%)$.

\subsubsection{Salt Affected}

Salt affected land is generally characterized as land that has adverse effects on plant growth due to the presence of excess soluble salts (saline) or high exchangeable sodium. Alkali land has an exchangeable sodium percentage (ESP) value of 15 or more, which is generally considered as the limit between normal and alkali soils. The predominant salts are carbonates and bicarbonates. They are essentially delineated because of their high reflectance. They appear in white to light blue colour depending upon the moisture content present. Majority parts of these features are confined to eastern parts of the study area. In the present study, the geographical extent of the salt-affected area is about $1.18 \mathrm{~km}^{2}(0.30 \%)$.

\subsubsection{Scrubland}

The land which is prone to deterioration due to erosion is termed as scrubland. These are associated with the foothills of the mountain range and plains with the moderate slope. They appear light yellow to brown and greenish blue in colour. Land with or without scrub usually associated with shallow, stony, rocky otherwise nonarable lands [28]. Two sub-categories are identified under this land category, as an open scrub and dense scrub.

\section{1) Open scrub}

This land is generally prone to deterioration due to erosion. They possess sparse vegetation or devoid of scrub and have thin soil covers. In the present study open scrub occupies an extent of about $11.98 \mathrm{~km}^{2}$ (3.08\%).

\section{2) Dense scrub}

These areas possess shallow and skeletal soils, at times chemically degraded, extremes of slopes, severely eroded and lands subjected to excessive aridity with scrubs dominating the landscape. They have a tendency for intermixing with cropped areas. In the present study, the geographical extent of the dense scrub is about 30.06 $\mathrm{km}^{2}(7.74 \%)$.

\section{Conclusions}

Being a very fast growing area Tirupati was chosen as a study area to quantify the LU/LC pattern for the year of 2012. The National LU/LC classification developed by NRSC and ISRO divides the land in the study area into 5 kinds of Level I class land type, 11 kinds of Level II class land type and 15 kinds of Level III class land type. The three level hierarchic based configurations reveal that the Forest land is the major LU/LC category in the Tirupati area covering $227.46 \mathrm{~km}^{2}$ (58.55\%), followed by agricultural land, wastelands, built up land and water bodies respectively, contributing $70.36 \mathrm{~km}^{2}$ (18.11) \%, $43.92 \mathrm{~km}^{2}(11.31 \%), 32.71 \mathrm{~km}^{2}(8.42 \%)$ and $14.03 \mathrm{~km}{ }^{2}$ (3.61\%) of the total geographical area. The study concludes that in the Tirupati area forest contributed the high- 
est (58.53\%), while the lowest was contributed by water bodies (3.61\%) and also finds the driving forces that show the considerable impact on the urban ecosystem.

The driving forces for the resulting spatial extent of these land use/land cover classes and their changes could be attributed to population growth, demands for forest products, demands for locally produced food, global issues such as higher energy prices and climate change in this study area. Moreover, future climate changes will potentially affect where humans live and how they use the land for various purposes. Our projection of human population growth suggests that urbanization will continue. This urbanization could further decrease the forests and croplands in the study area.

\section{Acknowledgements}

One of the authors E. Balaji is thankful to the Council of Scientific Industrial Research, New Delhi for providing the junior research fellowship (JRF).

\section{References}

[1] Rogan, J. and Chen, D.M. (2004) Remote Sensing Technology for Mapping and Monitoring Land-Cover and Land Use Change. Progress in Planning, 61, 301-325. http://dx.doi.org/10.1016/S0305-9006(03)00066-7

[2] Franklin, S.E. (2001) Remote Sensing for Sustainable Forest Management. Lewis Publishers, Boca Raton, 407 p. http://dx.doi.org/10.1201/9781420032857

[3] Franklin, J., Woodcock, C.E. and Warbington, R. (2000) Digital Vegetation Maps of Forest Lands in California: Integrating Satellite Imagery, GIS Modeling, and Field Data in Support of Resource Management. Photogrammetric Engineering and Remote Sensing, 66, 1209-1217.

[4] Dimyati, M., Mizuno, K. and Kitamura, T. (1996) An Analysis of Land Use/Cover Change Using the Combination of MSS Landsat and Land Use Map: A Case Study in Yogyakarta, Indonesia. International Journal of Remote Sensing, 17, 931-944. http://dx.doi.org/10.1080/01431169608949056

[5] Herold, M., Latham, J.S., Di Gregorio, A. and Schmullius, C. (2006) Evolving Standards in Land Cover Characterization. Journal of Land Use Science, 1, 157-168. http://dx.doi.org/10.1080/17474230601079316

[6] Song, K.S., Wang, Z.M., Liu, Q.F., Liu, D.W., Ermoshin, V.V., Ganzei, S.S., Zhang, B., Ren, C.Y., Zeng, L.H. and Du, J. (2011) Land Use/Land Cover (LULC) Classification with MODIS Time Series Data and Validation in the Amur River Basin. Geography and Natural Resources, 32, 9-15. http://dx.doi.org/10.1134/S1875372811010021

[7] Haines-Young, R. (2009) Land Use and Biodiversity Relationships. Land Use Policy, 26, S178-S186. http://dx.doi.org/10.1016/j.landusepol.2009.08.009

[8] Verburg, P.H., van de Steeg, J., Veldkamp, A. and Willemen, L. (2009) From Land Cover Change to Land Function Dynamics: A Major Challenge to Improve Land Characterization. Journal of Environmental Management, 90, 13271335. http://dx.doi.org/10.1016/j.jenvman.2008.08.005

[9] Perez-Soba, M., Petit, S., Jones, L., Bertrand, N., Briquel, V., Ormodei Zorini, L., Contini, C., Helming, K., Farrington, J.H., Tinacci Mossello, M., Wascher, D., Kienast, F. and De Groot, R. (2007) Land Use Functions-A Multifunctionality Approach to Assess the Impact of Land Use Change on Land Use Sustainability. In: Helming, K., Perez-Soba, M. and Tabbush, P., Eds., Sustainability Impact Assessment of Land Use Changes, Springer, 375-404.

[10] Haines-Young, R. (2000) Sustainable Development and Sustainable Landscapes: Defining a New Paradigm for Landscape Ecology. Fennia, 178, 7-14.

[11] De Groot, R. (2006) Function-Analysis and Valuation as a Tool to Assess Land Use Conflicts in Planning for Sustainable, Multi-Functional Landscapes. Landscape and Urban Planning, 75, 175-186. http://dx.doi.org/10.1016/j.landurbplan.2005.02.016

[12] Deng, X.Z., Liu, J.Y., Lin, Y.Z. and Shi, C.C. (2013) A Framework for the Land Use Change Dynamics Model Compatible with RCMs. Advances in Meteorology, 2013, Article ID: 658941, 7 p.

[13] He, J.F., Liu, J.Y., Zhuang, D.F., Zhang, W. and Liu, M.L. (2007) Assessing the Effect of Land Use/Land Cover Change on the Change of Urban Heat Island Intensity. Theoretical and Applied Climatology, 90, 217-226. http://dx.doi.org/10.1007/s00704-006-0273-1

[14] Seto, K.C. and Shepherd, J.M. (2009) Global Urban Land Use Trends and Climate Impacts. Current Opinion in Environmental Sustainability, 1, 89-95. http://dx.doi.org/10.1016/j.cosust.2009.07.012

[15] Bae, J. and Ryu, Y. (2014) Land Use and Land Cover Changes Explain Spatial and Temporal Variations of the Soil Organic Carbon Stocks in a Constructed Urban Park. Landscape and Urban Planning, 136, 57-67. http://dx.doi.org/10.1016/j.landurbplan.2014.11.015 
[16] Lambin, E.F., Turner, B.L., Geist, H.J., Agbola, S.B., Angelsen, A.J., Bruce, W., Coomes, O.T., Dirzo, R., Fischer, G.U., Folke, C., George, P.S., Homewood, K., Imbernon, J., Leemans, R., Li, X.B., Moran, E.F., Mortimore, M., Ramakrishnan, P.S., Richards, J.F., Skaness, H., Steffen, W., Stone, G.D., Svedin, U., Veldkamp, T.A., Vogel, C. and Xu, J.C. (2001) The Causes of Land Use and Land-Cover Change: Moving Beyond the Myths. Global Environmental Change, 11, 261-269. http://dx.doi.org/10.1016/S0959-3780(01)00007-3

[17] Brook, R.M. and Davila, J.D. (2000) The Peri-Urban Interface: A Tale of Two Cities. University of Wales and Development Planning Unit, University College London.

[18] Green, K., Kempka, D. and Lackey, L. (1994) Using Remote Sensing to Detect and Monitor Land Cover and Land Use Change. Photogrammetric Engineering and Remote Sensing, 60, 331-337.

[19] United Nations Population Fund (UNPF) (1991) Population, Resources and the Environment: The Critical Challenges. United Nations, New York.

[20] Praveen Kumar, M. and Sreenivasula Reddy, J.R. (2013) Analysis of Land Use/Land Cover Changes Using Remote Sensing Data and GIS at an Urban Area, Tirupati, India. The Scientific World Journal, 2013, Article ID: 268623.

[21] Anji Reddy, M. (2001) Textbook of Remote Sensing and Geographical Information Systems. BS Publications, Hyderabad.

[22] Selcuk, R., Nisanci, R., Uzun, B., Yalcin, A., Inan, H. and Yomralioglu, T. (2003) Monitoring Land-Use Changes by GIS and Remote Sensing Techniques: Case Study of Trabzon. Proceedings of 2nd FIG Regional Conference, Morocco, $1-11$.

[23] NRSC and ISRO (2011) Manual on "Preparation of Geo Spatial Layers Using High Resolution (Cartosat-1 Pan+LISS-IV Mx) Orthorectified Satellite Imagery”. Space Based Information Support for Decentralized Planning (SIS-DP), Remote Sensing and GIS Applications Area National Remote Sensing Centre, Indian Space Research Organisation (ISRO), Department of Space, Government of India, Hyderabad.

[24] Thomas, M.L. and Ralph, W.K. (2000) Remote Sensing and Image Interpretation. John Wiley and Sons Ltd., New York.

[25] Ode, A. and Fry, G. (2006) A Model for Quantifying and Predicting Urban Pressure on Woodland. Landscape and Urban Planning, 77, 17-27. http://dx.doi.org/10.1016/j.landurbplan.2005.01.003

[26] Ghosh, S., Sen, K.K., Rana, U., Rao, K.S. and Saxena, K.G. (1996) Applications of GIS for Land-Use/Land-Cover Change Analysis in a Mountainous Terrain. Journal of the Indian Society of Remote Sensing, 24, 193-202. http://dx.doi.org/10.1007/BF03007332

[27] Saha, S.K., Kudrat, M. and Bhan, S.K. (1990) Digital Processing of Landsat TM Data for Wasteland Mapping in Parts of Aligarh District (Uttar Pradesh), India. International Journal of Remote Sensing, 11, 485-492. http://dx.doi.org/10.1080/01431169008955034

[28] Gautam, N.C. and Narayanan, L.R.A. (1983) Landsat MSS Data for Land Use/Land Cover Inventory and Mapping: A Case Study of Andhra Pradesh. Journal of Indian Society of Remote Sensing, 11, 15-28. 